\title{
Efek Penambahan Aditif Golongan Karboksilat dalam Menghambat Laju Pembentukan Endapan Kalsium Sulfat
}

\author{
Suharso*) dan Buhani \\ Jurusan Kimia, Fakultas Matematika dan IImu Pengetahuan Alam, Universitas Lampung, \\ Jalan Sumantri Brojonegoro No. 1, Gedung Meneng-Bandarlampung 35145 \\ Diterima 15-01-2009 Disetujui 07-08-2010
}

\begin{abstract}
Scale formation is a serious problem encountered in many industries including oil or gas production, water transport, power generation and batch precipitation. Several additives used have been known to inhibit scale formation. This method is used because it is cheaper and effective in inhibiting scale formation. At this research, it was invesigated the effect of additional additive from carboxyl groups like citric acid, oxalate acid, and benzoic acid as inhibitor of kalsium sulfate $\left(\mathrm{CaSO}_{4}\right)$ scale formation using conductivity method at temperature of $40^{\circ} \mathrm{C}$. The result showes that additives used are able to inhibit kalsium sulfate $\left(\mathrm{CaSO}_{4}\right)$ scale formation under this condition.
\end{abstract}

Keywords: calcium sulfate, conductivity method, Inhibitor

\section{PENDAHULUAN}

Permasalahan yang dihadapi pada sebagian besar peralatan industri terutama pada dinding-dinding permukaan transfer panas dan permukaan alat-alat evaporasi, yaitu terjadinya penumpukan kerak. Penumpukan ini sangat tidak diinginkan karena mengurangi efisiensi dan mempersempit diameter pipapipa proses aliran fluida. Di samping itu, kerak yang menumpuk pada pipa-pipa saluran dapat mengakibatkan gangguan yang serius pada pengoperasian, karena penumpukan kerak ini dapat mengakibatkan terjadinya penyumbatan, kerusakan dan berujung kepada kebocoran (El Dahan \& Hegazy, 2000; Gal et al., 2002; Dyer \& Graham, 2003; Suharso et al., 2007). Akibatnya biaya produksi menjadi mahal karena harus memperbaiki dan mengganti komponen peralatan yang rusak. Selain itu produksi akan terganggu akibat perbaikan peralatan yang rusak.

Pada prinsipnya, pembentukan kerak terjadi dalam suatu aliran yang bersifat garam jika mengalami penurunan tekanan secara tiba-tiba, maka aliran tersebut akan menjadi lewat jenuh dan menyebabkan terjadinya endapan garam yang menumpuk pada dinding-dinding peralatan proses industri. Penumpukan endapan garam ini umumnya terdiri dari kalsium sulfat, fosfat dan karbonat (Amjad, 1995). Hal ini umum terjadi pada industri yang melibatkan air, seperti proses desalinasi dan ketel, pada industri minyak dan gas, serta industri kimia (Weijnen et al., 1983; Maley, 1999). Di samping kalsium karbonat, kalsium sulfat termasuk salah satu endapan yang mempunyai andil sebagai penyusun kerak pada sebagian besar peralatan industri. Untuk mengatasi permasalahan ini, sejumlah metode kontrol endapan kerak telah diteliti, yaitu dengan menurunkan $\mathrm{pH}$ larutan melalui penambahan asam atau water treatment. Namun demikian, penurunan $\mathrm{pH}$ larutan menggunakan asam-asam kuat bukanlah metode yang praktis dikarenakan asam kuat dapat meningkatkan laju korosi peralatan industri yang terbuat dari logam, sedangkan water treatment membutuhkan biaya yang sangat mahal. Solusi yang dianggap efektif dan berbiaya ringan oleh para peneliti yaitu dengan penambahan aditif antikerak (Amjad, 1998; Zhang \& Dawe, (2000); Manoli et al., (2003); Donachy \& Sikes, (1994); Jones et al., (2002), Choi et al., (2001), Suharso, et al., 2007). Selain itu Hamdona dan Hamza, (2009), menggunakan asam turunan ortofosfat dan polifosfat sebagai inhibitor $\mathrm{CaSO}_{4}$ dan Al-Mutairi et al., (2009), memanfaatkan asam etilendiamintetraasetat sebagai inhibitor pertumbuhan deposit $\mathrm{CaSO}_{4}$.

\footnotetext{
*Telp: +628154085313

Email: suharso_s@yahoo.com
} 
Aditif yang efektif dengan konsentrasi yang sangat kecil dalam satuan ppm mengadsorpsi ke dalam inti untuk memperlambat pertumbuhan kristal dengan cara menggantikan $\mathrm{SO}_{4}{ }^{2-}$ dan mengikat $\mathrm{Ca}^{2+}$ (Austin et al., 1975). Dalam penelitian ini akan dipelajari efek penggunaan aditif golongan karboksilat dalam menghambat laju pertumbuhan kristal kalsium sulfat berdasarkan metode konduktivimeter dan analisis morfologinya dilakukan dengan scanning electron microscopy (SEM). Adapun aditif yang digunakan adalah asam sitrat, asam oksalat dan asam benzoat.

\section{BAHAN DAN METODE}

Alat-alat yang digunakan dalam penelitian ini adalah alat-alat gelas laboratorium, konduktivitimeter merek Orion model 162, termometer, filter membran selulosa nitrat $0,45 \mu \mathrm{m}$ merek Whatman, cold plate merek Advantec, pengaduk magnet, pompa vakum Aspirator Pump model 7049-05, desikator, mikroskop merek Prior, dan scanning electron microscopy (SEM) merek Jeol JSM-5310 LV.

Bahan-bahan yang digunakan dalam penelitian ini adalah kalsium klorida $\left(\mathrm{CaCl}_{2}\right)$, sodium sulfat $\left(\mathrm{Na}_{2} \mathrm{SO}_{4}\right)$, aseton, akuades, dan aditif asam sitrat, asam oksalat dan asam benzoat. Semua bahan kimia yang digunakan berasal dari Aldrich Chemical Company, USA.

Preparasi bibit kristal. Bibit kristal dibuat dengan mencampurkan larutan $\mathrm{CaCl}_{2} 1 \mathrm{M}$ dan larutan $\mathrm{Na}_{2} \mathrm{SO}_{4} 1 \mathrm{M}$ masing-masing dalam $50 \mathrm{ml}$ akuades. Campuran diaduk hingga mengendap sempurna. Kemudian endapan dipisahkan melalui proses penyaringan menggunakan filter membran selulosa nitrat $0,45 \mu \mathrm{m}$. Kristal dicuci dengan akuades untuk menghilangkan sisa-sisa cairan induk dan kotoran. Kristal yang diperoleh dikeringkan dengan aseton. Selanjutnya kristal ini digunakan sebagai bibit kristal yang diamati pertumbuhannya.

Preparasi larutan pertumbuhan. Preparasi larutan pertumbuhan tanpa aditif. Larutan pertumbuhan dibuat dengan mencampurkan larutan $\mathrm{CaCl}_{2} 0,05 \mathrm{M}$ dan larutan $\mathrm{Na}_{2} \mathrm{SO}_{4}$ 0,05 $\mathrm{M}$ masing-masing dalam $100 \mathrm{ml}$ akuades. Campuran diaduk hingga menjadi larutan yang homogen, kemudian disaring dengan kertas saring. Selanjutnya larutan diletakkan di dalam gelas piala.

Preparasi larutan pertumbuhan dengan aditif. Larutan aditif dibuat 100 ppm untuk masing-masing aditif, yaitu asam sitrat, asam oksalat, dan asam benzoat. Selanjutnya dilakukan pengenceran untuk mendapatkan konsentrasi yang diperlukan, yaitu 0-100 ppm. Larutan pertumbuhan dibuat dengan mencampurkan larutan $\mathrm{CaCl}_{2}$ 0,05 M dan larutan $\mathrm{Na}_{2} \mathrm{SO}_{4}$ 0,05 $\mathrm{M}$ masing-masing dalam $100 \mathrm{ml}$ larutan aditif. Campuran diaduk hingga menjadi larutan yang homogen, kemudian disaring dengan kertas saring. Selanjutnya larutan diletakkan di dalam gelas piala.

Analisis dengan konduktivitimeter. Larutan pertumbuhan diletakkan ke dalam cold plate yang telah diatur temperaturnya sebesar $40^{\circ} \mathrm{C}$. Ketika temperatur larutan konstan, $1 \mathrm{~g}$ bibit kristal ditambahkan dengan cepat ke dalam larutan pertumbuhan yang menunjukkan titik nol pada penelitian ini. Selanjutnya keadaan ini dianggap sebagai konduktivitas awal dan perubahan konduktivitasnya diamati dalam selang waktu 10 menit selama 1 jam. Skema alat untuk analisis konduktivitas ditunjukkan pada Gambar 1. Pemisahan kristal kalsium sulfat Larutan pertumbuhan dengan aditif dan tanpa aditif setelah dianalisis dengan konduktivitimeter dipisahkan endapannya melalui proses penyaringan menggunakan filter membran selulosa nitrat $0,45 \mu \mathrm{m}$. Kristal yang diperoleh kemudian dicuci dengan akuades untuk menghilangkan sisa-sisa cairan induk dan kotoran. Selanjutnya kristal dikeringkan dengan aseton dan disimpan dalam desikator hingga benar-benar kering.

Analisis dengan scanning electron microscopy (SEM). Morfologi kristal diamati dengan menggunakan scanning electron microscopy (SEM) dengan perbesaran 3500 kali. Hasil pengamatan dengan scanning electron microscopy (SEM) dapat memberikan informasi perubahan morfologi kristal menggunakan larutan pertumbuhan tanpa aditif dan larutan pertumbuhan dengan penambahan aditif.

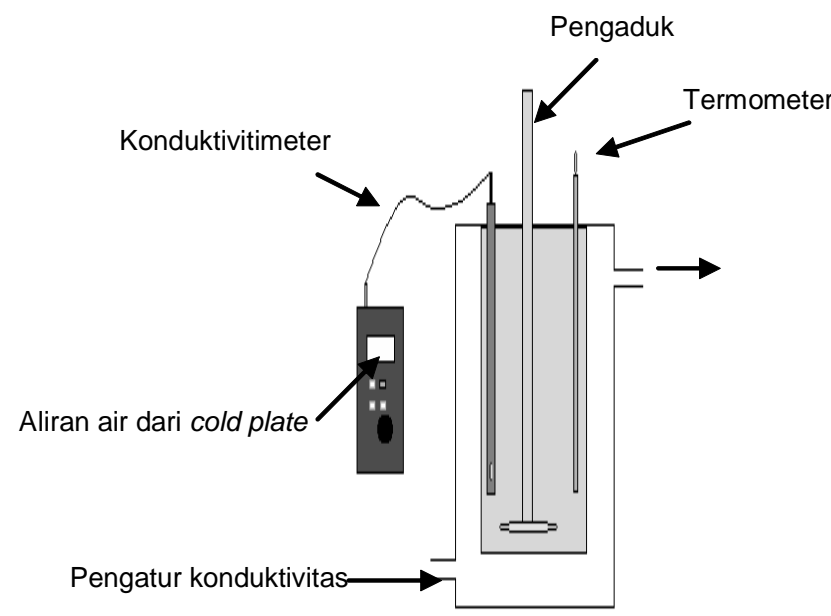

Gambar 1. Skema alat unt ;0, 2008) 


\section{HASIL DAN PEMBAHASAN}

Inhibitor pertumbuhan kristal adalah suatu senyawa yang ditambahkan pada media pertumbuhan, yang menyebabkan berkurangnya laju pertumbuhan. Langkah kerjanya adalah; mula-mula terjadi proses adsorbsi ion atau molekul adsorbat pada permukaan kristal, dan memberikan aksi perlindungan terhadap proses pertumbuhan. Inhibitor dapat berikatan dengan permukaan kristal melalui cara perpindahan elektron dari senyawa inhibitor ke kristal membentuk ikatan koordinasi. Pada gugus fungsi molekul organik yang mengandung pasangan elektron bebas, dimana gugus fungsi tersebut biasanya mengandung unsur golongan $\mathrm{V}$ dan VI. Penggunaan asam sitrat 100 ppm merupakan konsentrasi yang efektif dalam menghambat laju pertumbuhan kristal kalsium sulfat. Hal ini ditunjukkan dari kurva perubahan konduktivitasnya yang paling besar. Perubahan konduktivitas terhadap waktu adalah merupakan ukuran terjadinya reaksi kristalisasi, dengan demikian pengamatan terhadap efektivitas aditif yang ditambahkan dapat dilakukan.

Berdasarkan Gambar 2, asam sitrat 50 ppm tidak efektif dalam menghambat pertumbuhan kalsium sulfat karena perubahan konduktivitasnya berada dibawah kontrol. Penambahan asam sitrat $50 \mathrm{ppm}$ justru memberikan pengendapan kalsium sulfat menjadi lebih besar. Penggunaan asam sitrat $75 \mathrm{ppm}$ relatif tidak memberikan pengaruh terhadap perubahan konduktivitas dari larutan pertumbuhan kalsium sulfat. Hal ini menunjukkan bahwa aditif pada level konsentrasi ini tidak berpengaruh dalam menghambat pembentukan endapan kalsium sulfat.

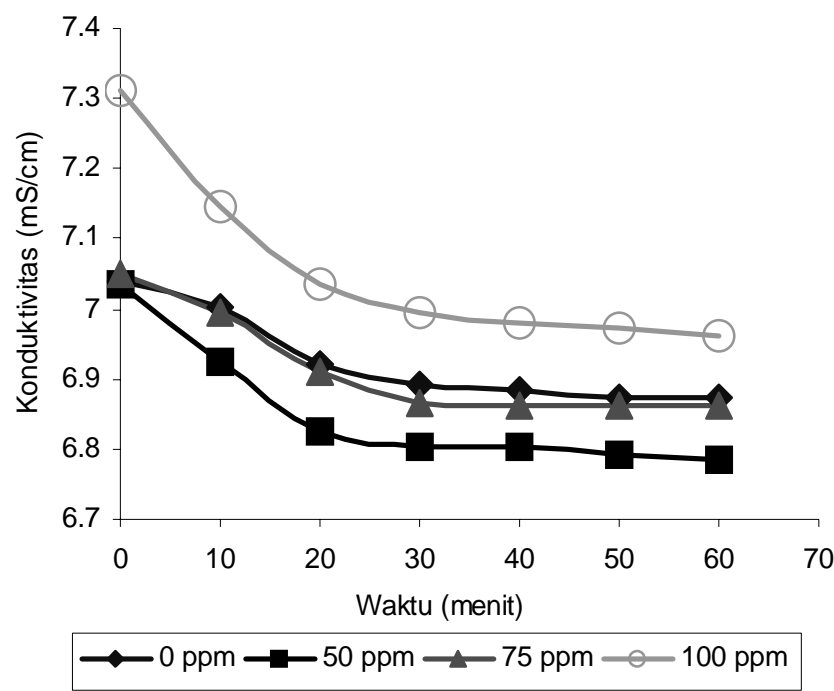

Gambar 2. Perubahan konduktivitas larutan pertumbuhan tanpa dan dengan menggunakan asam sitrat 50,75 , dan $100 \mathrm{ppm}$
Penjelasan yang mungkin dalam kasus ini adalah aditif pada konsentrasi ini tidak cukup tersedia dalam larutan pertumbuhan untuk mengadsorpsi pada permukaan pertumbuhan kristal, sehingga unit pertumbuhan kristal dari larutan pertumbuhan dapat melekat pada bibit kristal untuk melangsungkan pertumbuhan. Kasus ini terjadi pula pada penghambatan pertumbuhan kristal barium sulfat dengan asam metil fosfonat (Barouda et al., 2007) dan asam etilendiamin tetraasetat (Jones et al., 2007). Dalam penelitian ini, aditif mulai efektif bekerja pada permukaan pertumbuhan kristal pada konsentrasi 100 ppm. Pada level konsentrasi ini aditif mampu mengadsorpsi permukaan kristal sehingga unit pertumbuhan kristal baru terhalang untuk melekat pada permukaan bibit kristal, akibatnya laju pertumbuhan kalsium sulfat dapat dikurangi. Hal yang sama dapat juga diamati pada penambahan aditif asam benzoat dan asam oksalat dalam penelitian ini. Kasus ini dapat dibandingkan pada mekanisme pertumbuhan kristal barium sulfat pada penambahan asam nitriloasetat (Jones et al., 2006) dan mekanisme pertumbuhan kalsium karbonat pada penambahan asam benzoat (Freeman et al., 2006).

Kemampuan asam oksalat dalam menghambat laju pertumbuhan kristal kalsium sulfat dapat diamati dalam Gambar 3, gambar ini menunjukkan bahwa konsentrasi 75 dan 100 ppm merupakan konsentrasi efektif sebagai inhibitor. Dari Gambar 3 juga terlihat bahwa semakin besar konsentrasi asam oksalat, maka kemampuan inhibitor semakin besar. Penggunaan asam oksalat 25 dan 50 ppm tidak cukup efektif untuk menghambat laju pertumbuhan kristal kalsium sulfat.

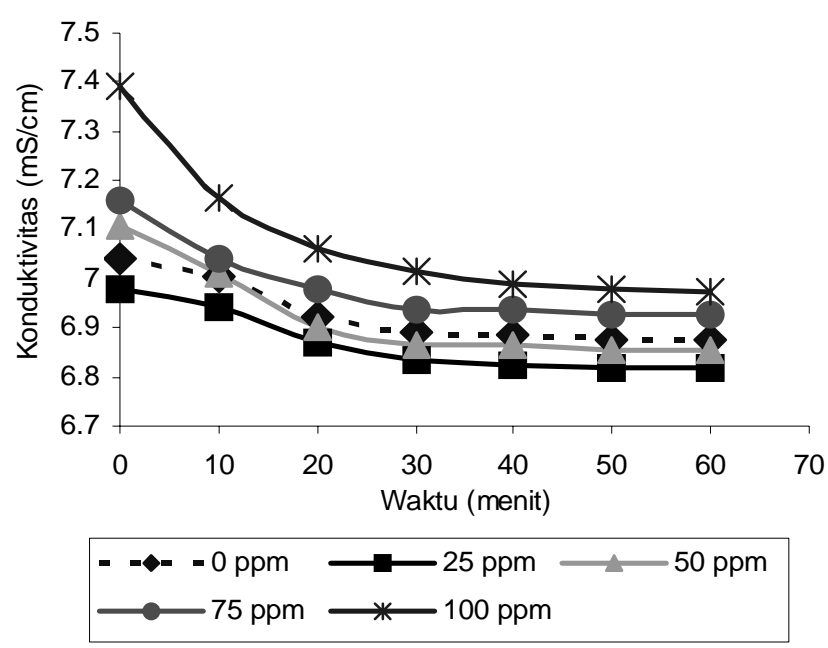

Gambar 3. Perubahan konduktivitas larutan pertumbuhan tanpa dan dengan menggunakan asam oksalat 25, 50, 75, dan $100 \mathrm{ppm}$ 
Dari Gambar 4 terlihat bahwa konsentrasi asam benzoat 25 dan 50 ppm merupakan konsentrasi yang cukup efektif dalam menghambat pertumbuhan kristal kalsium sulfat. Tetapi bila dibandingkan, konsentrasi 50 ppm mempunyai keefektifan yang lebih besar sebagai inhibitor. Hal ini terlihat dari kurvanya yang jauh berada diatas kontrol. Pada konsentrasi 75 ppm tidak memberikan hambatan terhadap pertumbuhan kalsium sulfat.

Analisa morfologi kristal kalsium sulfat setelah menggunakan asam benzoat $50 \mathrm{ppm}$ menunjukkan ukuran kristal yang lebih kecil dibandingkan kontrol (Gambar 6). Perubahan ukuran ini terlihat signifikan, konsisten dengan perubahan konduktivitasnya yang berada jauh diatas kontrol. Berdasarkan Gambar 5 diketahui inhibitor yang paling efektif adalah asam benzoat 50 ppm. Hal ini ditunjukkan oleh kurva perubahan konduktivitasnya yang berada jauh diatas kontrol. Sedangkan 100 ppm asam oksalat dan asam sitrat memiliki kemampuan yang relatif hampir sama dalam menghambat pembentukan endapan kalsium sulfat.

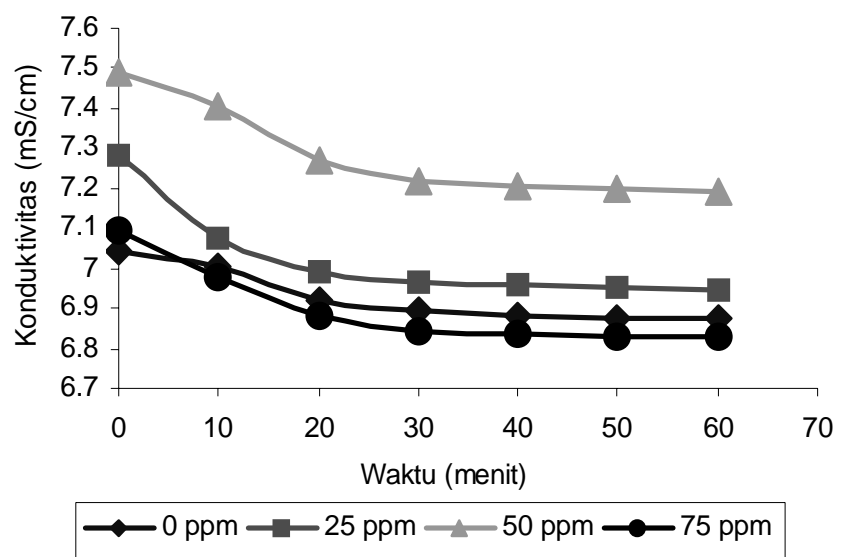

Gambar 4. Perubahan konduktivitas larutan pertumbuhan tanpa dan dengan menggunakan asam benzoat 25,50 , dan 75 ppm
Hasil analisa terhadap permukaan morfologi kristal kalsium sulfat dengan fotomikroskop setelah menggunakan inhibitor, yaitu pada pembesaran 600 kali terlihat adanya perbedaan ukuran dibandingkan morfologi kristal kalsium sulfat tanpa menggunakan inhibitor. Penggunaan asam sitrat dan asam oksalat 100 ppm tidak memberikan pengaruh yang signifikan terhadap morfologi kristal kalsium sulfat, hal ini konsisten dengan perbedaan perubahan konduktivitasnya yang tidak terlalu mencolok dengan kontrol. Gambar 5 jelas memperlihatkan perbedaan perubahan konduktivitas asam benzoat $50 \mathrm{ppm}$ terhadap kontrol. Penggunaan asam benzoat $50 \mathrm{ppm}$ pada larutan pertumbuhan memberikan konduktivitas paling besar, maka dapat diasumsikankan kristal yang tumbuh paling sedikit. Hasil penelitian ini sejalan dengan penelitian yang telah dilakukan oleh Jones et al., (2005), dalam material anorganik dengan menggunakan inhibitor turunan senyawa kaliks[4]arena. Pengaruh aditif dalam menghambat laju pertumbuhan kristal juga dapat diamati pada kristal borak (Suharso et al., 2007).
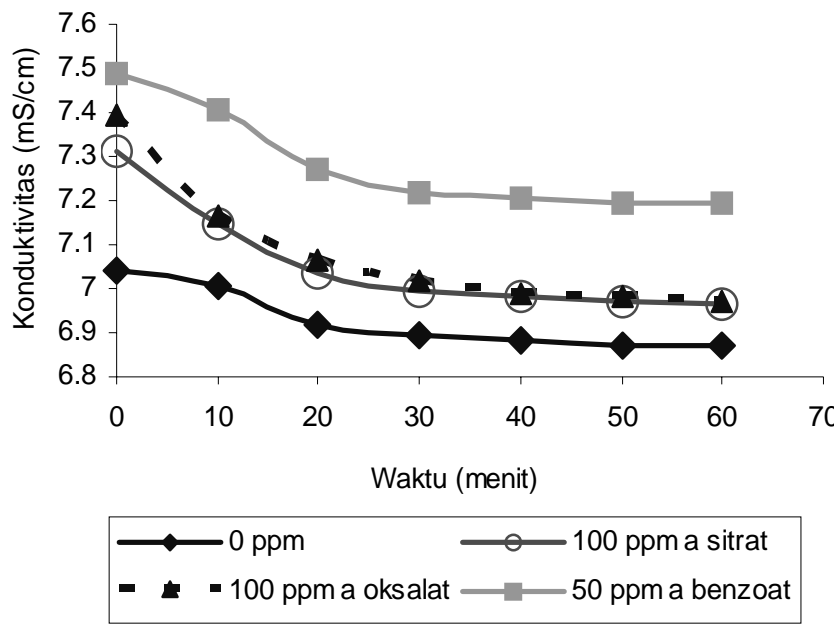

Gambar 5. Perubahan konduktivitas larutan pertumbuhan tanpa dan dengan menggunakan aditif yang efektif sebagai inhibitor pertumbuhan kalsium sulfat

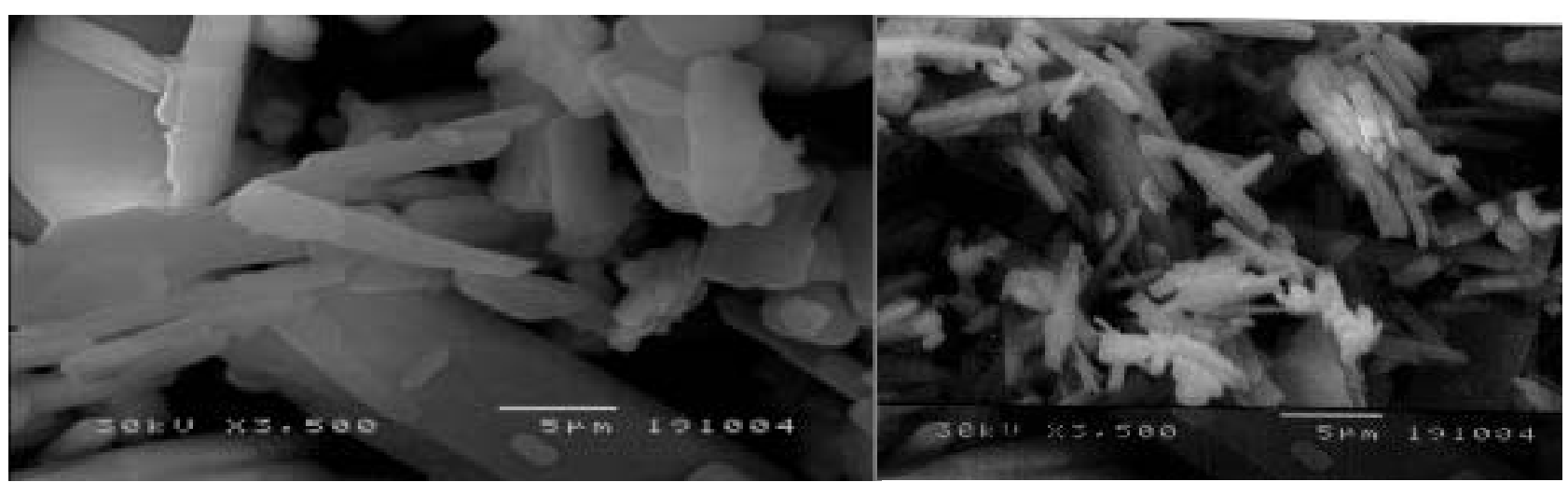

Gambar 6. Hasil pemotretan terhadap morfologi permukaan kalsium sulfat tanpa aditif dan dengan penambahan 50 ppm asam benzoat menggunakan scanning electron microscopy (SEM) dengan perbesaran 3500 kali 
Hasil pemotretan menggunakan SEM memberikan tampilan morfologi permukaan kristal yang lebih jelas. Gambar 6 menunjukkan perbedaan ukuran kristal tanpa menggunakan aditif (kontrol) dan dengan menggunakan aditif asam benzoat 50 ppm. Berdasarkan hasil pengamatan menggunakan konduktivitimeter dan SEM, asam benzoat $50 \mathrm{ppm}$ adalah aditif yang memberikan pengaruh terbesar dalam menghambat pertumbuhan kalsium sulfat.

\section{KESIMPULAN}

Penggunaan beberapa jenis aditif dari golongan karboksilat seperti asam sitrat, asam oksalat, dan asam benzoat sebagai aditif memberikan pengaruh terhadap laju pertumbuhan kristal kalsium sulfat. Penggunaan aditif yang efektif sebagai inhibitor mengakibatkan terjadinya perubahan konduktivitas menjadi lebih besar dan ukuran kristal kalsium sulfat menjadi lebih kecil dibandingkan tanpa menggunakan aditif. Konsentrasi menentukan tingkat keefektifan aditif sebagai inhibitor. Penggunaan asam benzoat $50 \mathrm{ppm}$ mempunyai aktivitas terbesar dalam menghambat pertumbuhan kristal kalsium sulfat.

\section{UCAPAN TERIMA KASIH}

Penulis dengan ini mengucapkan terima kasih kepada kepala Laboratorium Kimia Anorganik dan Kimia Fisik (Dr. Sutopo Hadi) atas fasilitas dan tempat penelitian yang disediakan.

\section{DAFTAR PUSTAKA}

Al-Mutairi, N.N., Aleem, F.A. \& Al-Ahmad, M.I. 2009. Effect of antiscalants for inhibition of calcium sulfate deposition in thermal desalination systems. Desalination and Water Treatment 10: 39-46.

Amjad, Z. 1995. Mineral Scale Formation And Inhibition. Plenum Press. New York

Amjad, Z. 1998. Water Soluble Polymers: Solution Properties and Applications. Plenum Press. New York.

Austin, A.E., Miller, J.F.D, Vaughan, A. \& Kircher, J.F. 1975 Chemical Additives For Calsium Sulphate Scale Control. Desalination 16: 345-357.

Barouda, E., Demadis, K.D., Freeman, S.R., Jones, F. \& Ogden, M.I. 2007. Barium Sulfate Crystallization in the Presence of Variable Chain Length Aminomethylenetetraphosphonates and Cations ( $\mathrm{Na}+$ or Zn2+). Crystal Growth \& Design 7(2): 321-327.

Choi, D.J., You, S.J. \& Kim, J.G. 2001. Development Of An Environmentally Safe Corrosion, Scale, And Microorganism
Inhibitor For Open Recirculating Cooling Systems. Material Science and Engineering A 335(1-2): 228-235.

Donachy, J.E., \& Sikes, C.S. 1994. Thermal Polycondensation Synthesis of Biomimetic Serine-Containing Derivatives Polyaspartate: Potent Inhibitors of Calsium Carbonate Phosphate Crystallisation. Journal of Polymer Science 32: 789-795

Dyer, S.J. \& Graham, G.M. 2003. Thermal Stability Of Generic Barium Sulphate Scale Inhibitor Species Under Static And Dynamic Conditions. Journal of Petroleum Science and Engineering 37: 171-181.

El Dahan, H.A. \& Hegazy, H.S. 2000. Gypsum Scale Control By Phosphate Ester. Desalination 127: 111-118.

Freeman, S.R., Jones, F., Ogden, M.I., Oliviera, A. \& Richmond, W.R. 2006. Effect of benzoic acids on barite and calcite precipitation. Crystal. Growth \& Design 6(11): 2579-2587.

Gal, J.Y., Fovet, Y. \& Gatche, N. 2002. Mechanism Of Scale Formation And Carbon Dioxide Partial Pressure Influence. Part I. Elaboration Of An Experimental Method And Scaling Model. Water Research 36: 755-763.

Hamdona, S.K. \& Hamza, S.M. 2009. Influence of some phosphates and polyphosphates on the precipitation of calcium sulfate dihydrate in sodium chloride solutions. Journal of Taibah University for Science 2: 44-51.

Jones, F., Oliveira, A., Rohl, A.L., Ogden, M.I. \& Parkinson, G.M. 2006. Understanding the mechanism by which nitrilotriacetic acid interacts with precipitating barium sulfate. CrystEngComm 8: 869-876.

Jones, F, Jones, P., Ogden, M.I., Richmond, W.R., Rohl, A.L. \& Saunders, M. 2007. The interaction of EDTA with barium sulfate. Journal Colloid and Interfacace Science 316(2): 553-561.

Jones, F., Mocerino, M., Ogden, M.I., Oliveria, A. \& Parkinson, G.M. 2005. Bio-inspired calix[4]arene additives for crystal growth modification of inorganic materials. Crystal Growth and Design 5: 2336-2343.

Jones, F., Oliveria, A., Rohl, A.L., Parkinson, G.M., Ogden, M.I. \& Reyhani, M.M. 2002. Investigation Into The Effect Of Phosphonate Inhibitors On Barium Sulfate Precipitation. Journal of Crystal Growth 237-239(1): 424-429.

Maley, M. 1999. Inhibition Of Calcite Nucleation And Growth Using Phosphonate. Curtin University of Technology Western Australia. Australia.

Manoli, F., Kanakis, J., Malkaj, P. \& Dalas, E. 2003. The Effect Of Aminoacids On The Crystal Growth Of Calcium Carbonate. Journal of Crystal Growth 236(1-3): 363-370.

Suharso. 2008. Mechanism of Borax Crystallization Using Conductivity Method. Indonesian Journal of Chemistry 8(3): 327-330.

Suharso, Buhani, Suhartati, T. \& Aprilia, L. 2007. SintesiscMetil-4,10,16,22-Tetrametoksi Kaliks[4]Arena dan Peranannya Sebagai Inhibitor Pembentukan Kerak Kalsium Karbonat $\left(\mathrm{CaCO}_{3}\right)$. Laporan Akhir Program Insentif, Unversitas Lampung, Bandar Lampung.

Suharso, Parkinson, G. \& Ogden, M. 2007. Effect Of Cetyltrimehylammonium Bromide (CTAB) On The Growth Rate and Morphology Of Borax Crystals. Journal of Applied Sciences 7(10): 1390-1396.

Weijnen, M.P.C., Marchee W.G.J. \& van Rosmalen G.M. 1983. A Quantification Of The Effectiveness Of An Inhibitor On The Growth Process Of A Scalant. Desalination 47: 81-92.

Zhang, Y. \& Dawe, R.A. 2000. Influence Of $\mathrm{Mg}^{2+}$ On The Kinetics Of Calcite Precipitation and Calcite Crystal Morphology. Chemical Geology 163: 129-138. 